\title{
The Action of Streptomycins on the Chloroplast System of Euglena gracilis
}

\author{
By L. EBRINGER, J. L. MEGO, A. JURÁŠEK \\ AND R. KADA \\ Department of Microbiology, \\ Komensky University and The Department of Organic Chemistry, \\ Slovak Polytechnic University, Bratislava, Czechoslovakia
}

\section{(Accepted for publication 23 August 1969)}

\begin{abstract}
SUMMARY
Five streptomycins bleached the chloroplast system of Euglena gracilis; the most effective were those which contained an aldehyde group in the streptose moiety: streptomycin and hydroxystreptomycin. Derivatives containing a secondary alcohol group in place of the aldehyde (dihydro-, dihydrodesoxy-, dihydrohydroxystreptomycin) require higher concentrations to elicit the same effect. Hydroxylamine reversed the bleaching effects of streptomycin and hydroxystreptomycin but not of dihydro-, dihydrodesoxy- or dihydrohydroxystreptomycin. These observations suggest that the aldehyde group of the streptomycins contributes to the action of these antibiotics on Euglena chloroplasts; the action of hydroxylamine would be to either remove the antibiotic from its site of action or to render it ineffective in vivo by reaction with the aldehyde group.
\end{abstract}

\section{INTRODUCTION}

An interesting and as yet inadequately explained action of streptomycin is the ability of this antibiotic to eliminate chloroplasts from Euglena without significantly inhibiting cell division or viability of the cell. In bacteria, streptomycin binds to ribosomes causing miscoding of messenger RNA and production of faulty protein (Davies, Gilbert \& Gorini, I964). Accordingly, Schiff \& Epstein (1965) suggested that bleaching agents may act by inhibiting protein synthesis in Euglena chloroplasts. However, Stern, Barner \& Cohen (1966) demonstrated that, in Escherichia coli, streptomycin lethality occurred in the absence of protein synthesis. Since the Euglena chloroplast represents a different system in which to study the mechanism of action of antibiotics, further light may be shed on this important subject by the use of this organism.

Aronson, Meyer \& Brock (1964) proposed a mechanism of action for the streptomycins based on the ability of the antibiotics to cross-link nucleic acid. Streptomycin is a more effective cross-linking agent in vitro than dihydrostreptomycin, and the presence of an aldehyde group in the streptose moiety may be responsible for the increased effectiveness. According to Aronson et al. (I964), this aldehyde is capable of forming a second cationic attachment site by reacting with the secondary amino group at the $\mathrm{N}$-methyl glucosamine moiety, resulting in a cyclic iminium salt. Since dihydrostreptomycin cannot form this cationic cyclic structure, it would be expected to be a less effective agent for precipitating nucleic acids. Streptomycin is known to be more effective as a bleaching agent in Euglena than dihydrostreptomycin (Zahalsky, 
Hutner, Keane \& Burger, I962), which supports the model of Aronson et al. (I964) and suggests that the aldehyde group may play a role in chloroplast elimination. We have observed that hydroxylamine reverses the action of streptomycin in Euglena chloroplasts if added before about 6 to 8 divisions have taken place in the presence of the antibiotic (Ebringer, Mego \& Podová, 1967). In the studies reported in the present paper we compared the actions of five streptomycins as bleaching agents in Euglena. These antibiotics differ only in the streptose moiety: some contain aldehyde groups and others have alcoholic groups. We also considered it of interest to compare the effect of hydroxylamine as a reversing agent on the action of these streptomycins particularly since hydroxylamine may react with the aldehyde to form an oxime.

\section{METHODS}

Euglena gracilis, strain z, was grown in a proteose peptone-tryptone medium (Mego, 1964). Cultivation conditions were described by Ebringer (1966). Antibiotics were dissolved in distilled water, sterilized by filtration and then added to the liquid media. After a period of growth with antibiotic, the organisms were washed, harvested by centrifugation and then plated. On the ninth day after plating about 300 to 600 colonies were counted and the numbers of white and green colonies were recorded. Individual counts were made microscopically in a Burker counting chamber.

The final concentration of hydroxylamine sulphate was always $10^{-1} \mathrm{M}$. Hydroxylamine was present for only $20 \mathrm{~min}$. and was then removed by washing on the centrifuge. The chlorophyll content was determined according to the method of Arnon (1949). Sulphates of the streptomycins were obtained by the courtesy of the following: dihydrodesoxystreptomycin sulphate from Dr Kazuo Kagiwada, Kaken Chemical Co. Ltd., Tokyo, Japan; hydroxy- and dihydrohydroxystreptomycin sulphate from Dr J. C. Sylvester, Abbott Laboratories, North Chicago, Illinois, U.S.A; dihydrostreptomycin sulphate, from Dr Alvaro Zugaza, Antibiotics, S.A. Madrid, Spain.

The following abbreviations will be used: SM, streptomycin; OHSM, hydroxystreptomycin; DHSM, dihydrostreptomycin; DHOHSM, dihydrohydroxystreptomycin; DHDSM, dihydrodesoxystreptomycin; HA, hydroxylamine.

\section{RESULTS}

Figure I shows that bleaching action of the various streptomycins depended on the concentration and duration of action. The most effective were SM and OHSM, which produced $100 \%$ bleached colonies in $24 \mathrm{hr}$ at $500 \mu \mathrm{g}$. $/ \mathrm{ml}$., in 3 days at $100 \mu \mathrm{g} . / \mathrm{ml}$, , only after 5 days at $10 \mu \mathrm{g}$. $/ \mathrm{ml}$. DHSM, DHOHSM and DHDSM, however, required 4 days to produce $100 \%$ bleached colonies at $500 \mu \mathrm{g} . / \mathrm{ml}$. Even after 6 or more days these antibiotics did not produce total bleaching at $10 \mu \mathrm{g} . / \mathrm{ml}$.

Table I shows that OHSM inhibited growth slightly more than the other antibiotics. In order to diminish this toxicity effect, we used $100 \mu \mathrm{g} . / \mathrm{ml}$. in further experiments since this concentration produced total bleached colonies. SM was used in this concentration, while DHSM, DHOHSM and DHDSM were used at $500 \mu \mathrm{g} . / \mathrm{ml}$.

Hydroxylamine reversed only the effects of SM and OHSM (Table 2). The reversal was nearly complete when this agent was added before 4.5 divisions. After about 5 divisions only a small percentage of the organisms were reversed. Reversal effectiveness 

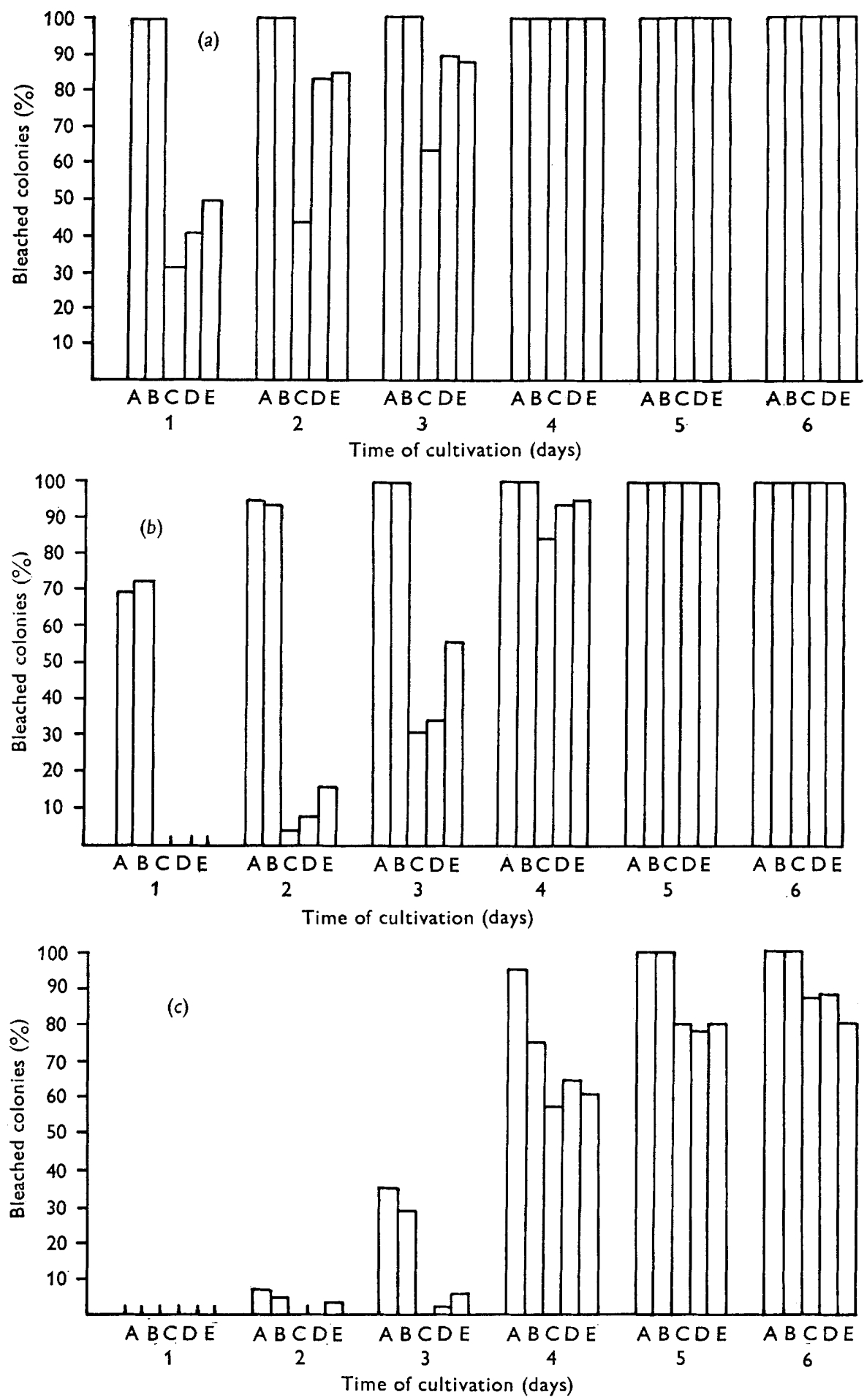

Fig. I. Proportions of bleached colonies obtained after growth of Euglena gracilis in various concentrations of streptomycins for varying lengths of time. (a) $500 \mu \mathrm{g} . / \mathrm{ml}$, (b) $100 \mu \mathrm{g} . / \mathrm{ml}$. (c) $10 \mu \mathrm{g} . / \mathrm{ml}$. After the indicated period of cultivation with the streptomycins, the organisms were washed, plated on antibiotic-free media and bleached and green colonies counted after 9 days. A, SM; B, OHSM; C, DHSM; D, DHOHSM; E, DHDSM (for abbreviations, see text). 
was approximately the same for SM and OHSM but completely ineffective for the other antibiotics.

Table 3 shows the chlorophyll content of the cultures during growth in the presence of the various antibiotics. Although $100 \%$ of bleached colonies were obtained after plating in many cases, the cultures contained considerable quantities of chlorophyll. These results suggest that chlorophyll content of the cultures does not represent a true measure of the bleaching effectiveness of these agents.

Table I. Effects of various streptomycins on growth of Euglena gracilis

$\begin{array}{llllr}\text { Antibiotic }(\mu \mathrm{g} . / \mathrm{ml} .) \ldots & 500 & 200 & 100 & \text { I0 } \\ \text { SM } \dagger & 438^{*} & 440 & 530 & 572 \\ \text { OHSM } & 355 & 398 & 446 & 485 \\ \text { DHSM } & 418 & 470 & 520 & 536 \\ \text { DHOHSM } & 460 & 497 & 510 & 560 \\ \text { DHDSM } & 400 & 468 & 550 & 575\end{array}$

* The numbers represent thousands of organisms $/ \mathrm{ml}$. medium after 6 days at $24^{\circ}$. $\dagger$ For abbreviations see text.

Table 2. Prevention of streptomycin-bleaching of

Euglena gracilis by hydroxylamine

Organisms in media containing streptomycins were allowed to grow for approximately the numbers of divisions in column I. Samples were removed, treated with HA for 20 min., washed and plated on agar (column ' $+\mathrm{HA}^{\prime}$ '). The column ' $-\mathrm{HA}^{\prime}$ ' indicates the results without hydroxylamine treatment. Colonies were counted after 9 days growth on agar at $24^{\circ}$.

$\%$ permanently bleached colonies

\begin{tabular}{|c|c|c|c|c|c|c|c|c|c|c|}
\hline \multirow{2}{*}{$\begin{array}{l}\text { Numbers of } \\
\text { divisions }\end{array}$} & \multicolumn{2}{|c|}{$\mathrm{IM}^{\text {SM }}$} & \multicolumn{2}{|c|}{ OHSM } & \multicolumn{2}{|c|}{ DHSM } & \multicolumn{2}{|c|}{ DHOHSM } & \multicolumn{2}{|c|}{ DHDSM } \\
\hline & - HA & $+\mathrm{HA}$ & $\widehat{-H A}$ & $+\mathbf{H A}$ & $-\mathrm{HA}$ & $+\mathrm{HA}$ & $-{ }_{-\mathrm{HA}}$ & $+\mathrm{HA}$ & $-\mathbf{H A}$ & $+\mathrm{HA}$ \\
\hline $1 \cdot 0$ & 87 & 8 & 93 & 4 & 25 & 26 & 40 & 48 & 52 & 49 \\
\hline $2 \cdot 5$ & 100 & I & 100 & 7 & 40 & 39 & 64 & 63 & 57 & 62 \\
\hline $3 \cdot 9$ & 100 & I & 100 & 2 & 63 & 59 & 80 & 80 & 85 & 89 \\
\hline $4 \cdot 5$ & 100 & 2 & 100 & 2 & 84 & 86 & 91 & 92 & 9 I & 95 \\
\hline 4.9 & 100 & 40 & 100 & 50 & 100 & 100 & 100 & 100 & 100 & 100 \\
\hline $5 \cdot 4$ & 100 & 93 & 100 & 98 & 100 & 100 & 100 & 100 & 100 & 100 \\
\hline 5.9 & 100 & 100 & 100 & 100 & 100 & 100 & 100 & 100 & 100 & 100 \\
\hline
\end{tabular}

For abbreviations and concentrations see text.

Table 3. Chlorophyll content (as \% of a control culture without added antibiotic) of Euglena gracilis and the percent streptomycin-bleached colonies obtained 9 days after plating on agar

\begin{tabular}{|c|c|c|c|c|c|c|c|c|}
\hline Antibiotic $(\mu \mathrm{g} . / \mathrm{ml})$. & $\begin{array}{c}500 \\
\text { Chloro- } \\
\text { phyll }\end{array}$ & Colonies & $\begin{array}{c}200 \\
\text { Chloro- } \\
\text { phyll }\end{array}$ & Colonies & $\begin{array}{c}\text { I0o } \\
\text { Chloro- } \\
\text { phyll }\end{array}$ & Colonies & $\begin{array}{c}\text { IO } \\
\text { Chloro- } \\
\text { phyll }\end{array}$ & Colonies \\
\hline SM & 0 & 100 & 0 & 100 & 0 & 100 & 29 & 100 \\
\hline OHSM & 0 & 100 & 0 & 100 & 0 & 100 & 69 & 100 \\
\hline DHSM & 21 & 100 & 30 & 100 & 36 & 100 & 86 & 87 \\
\hline DHOHSM & 26 & 100 & 35 & 100 & 43 & 100 & 55 & 85 \\
\hline DHDSM & 31 & 100 & 32 & 100 & 33 & 100 & 61 & 79 \\
\hline
\end{tabular}

For details and abbreviations see text. 


\section{DISCUSSION}

The results presented in this paper establish that those streptomycins containing an aldehyde group on the streptose moiety were the most effective bleaching agents (see Fig. 2) and support the model proposed by Aronson et al. (1964) discussed in the introduction. There is no direct evidence yet to suggest that these antibiotics bind directly to chloroplast DNA; however, some mechanism must be proposed to account for the ability of streptomycin permanently to eliminate chloroplasts from Euglena. Zimmer, Triebel \& Thrum (1967) have shown that certain antibiotics, including streptomycin and dihydrostreptomycin, interact with DNA in vitro to increase the melting
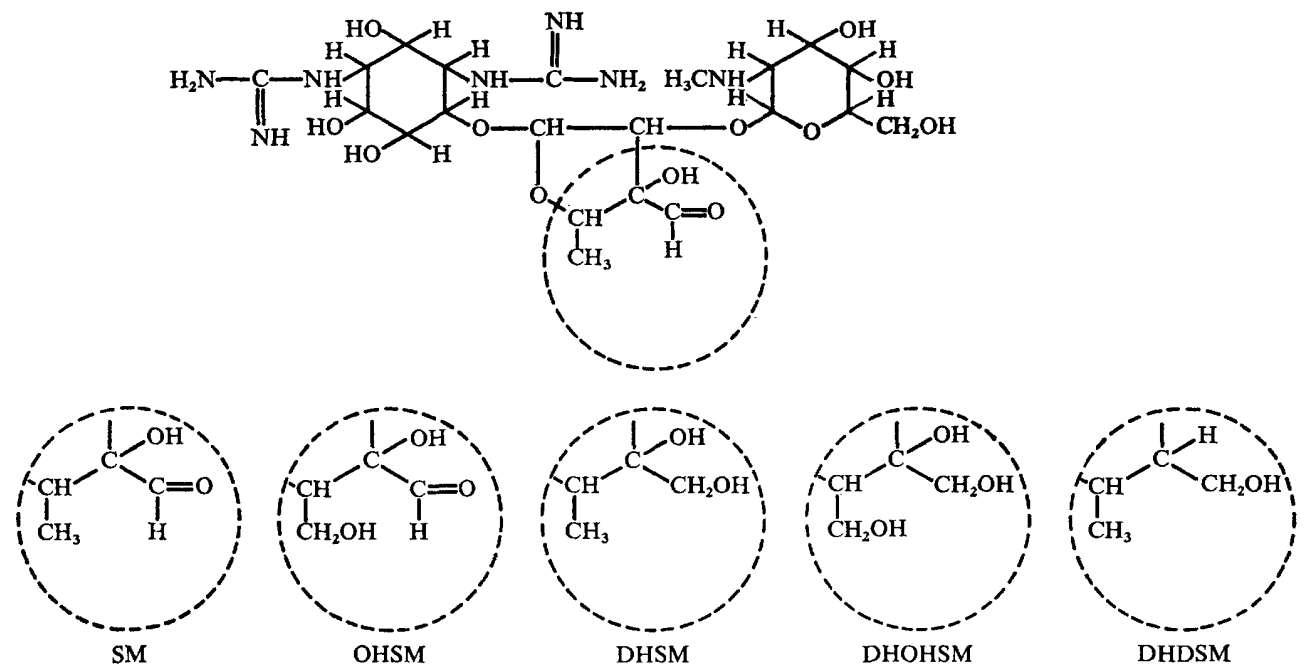

Fig. 2. The structures of streptomycins.

point of this nucleic acid. Their evidence suggests that the antibiotics cross-link DNA by electrostatic interactions. It does not seem unreasonable, therefore, to postulate that the antibiotics may prevent the separation of DNA strands after replication in the chloroplast. Hydroxylamine may act by releasing the antibiotics from electrostatic interaction with chloroplast DNA perhaps by reacting with the aldehyde group. This hypothesis would require either a different mechanism of action for the non-aldehydecontaining antibiotics or a less efficient binding to DNA.

Approximately six divisions were required before treatment with hydroxylamine became ineffective as a reversing agent. This correlates with the observation of Mego \& Buetow (1967), who found that approximately this number of divisions was required for irreversible chloroplast loss induced by growth at elevated temperature. Again, it does not seem unreasonable to postulate that inhibition of DNA replication may require this number of divisions to 'dilute out' the relevant nucleic acid.

Other inhibitors of DNA synthesis are also effective bleaching agents in Euglena. These include nalidixic acid, porfiromycin, streptonigrin, novobiocin, rubiflavin, sarkomycin (Ebringer \& Mego, unpublished observations), some mutagens (McCalla, I967) and ultraviolet light (Lyman, Epstein \& Schiff, I96r; Gibor \& Granick, I962). An argument against the theory that bleaching agents act by inhibition of protein 
synthesis in chloroplasts is the effect of chloramphenicol. This antibiotic is effective only in organisms containing $70 \mathrm{~S}$ ribosomes (Vazquez \& Monro, 1967) including Euglena chloroplasts. Chloramphenicol has no effect on protein synthesis in the cytoplasm of Euglena which contains $80 \mathrm{~S}$ ribosomes. This substance, therefore, should be an ideal bleaching agent, since rapid cell division can proceed while chloroplast protein synthesis is inhibited. Chloramphenicol is not a bleaching agent, however, and only produces a temporary inhibition of chloroplast protein formation (Anderson \& Smillie, 1966; Pogo \& Pogo, 1965). Other inhibitors of protein synthesis such as the tetracyclines and puromycin are also not effective bleaching agents (Selsky, 1967). Although aureomycin has been reported to cause bleaching of Euglena (Robbins, Hervey \& Stebbins, I953), we have not been able to demonstrate more than a temporary inhibition of chloroplast formation under a variety of conditions.

We have also presented evidence that measurement of chlorophyll may not always be a valid index of permanent bleaching effectiveness of antibiotics. This may account for the observations of Linnane \&'Steward (1967) in which these authors reported that macrolidic antibiotics were not bleaching agents in Euglena.

Dr J. L. Mego is a participant in the U.S.A. and Czechoslovak Academies of Sciences Exchange Programme. Present address: Department of Biology, The University of Alabama, Alabama 35486.

The authors gratefully acknowledge the assistance of Miss Gabriela Smutná.

\section{REFERENCES}

Anderson, L. A. \& SMillie, R. M. (1966). Binding of chloramphenicol by ribosomes from chloroplasts. Biochem. biophys. Res. Commun. 23, 535.

Arnon, D. (I949). Copper enzymes. Pl. Physiol. 24, I.

Aronson, J., Meyer, W. L. \& Brock, T. D. (1964). A molecular model for chemical and biological differences between streptomycin and dihydrostreptomycin. Nature, Lond. 202, 555 .

Davies, J., Gilbert, W. \& Gorini, L. (1964). Streptomycin, suppression, and the code. Proc. natn. Acad. Sci. U.S.A. 51, 883 .

Ebringer, L. (1966). Antibiotics and apochlorosis. I. Macrolide antibiotics-their common molecular structure responsible for bleaching of Euglena gracilis. Folia microbiol., Praha II, 379.

Ebringer, L., Mego, J. L. \& PodovÁ, M. (I967). Reversal of streptomycin bleaching of Euglena gracilis by mutagenic concentrations of hydroxylamine. Biochem. biophys. Res. Commun. $29,57 \mathrm{I}$.

Gibor, A. \& Granick, S. (1962). Ultraviolet sensitive factors in the cytoplasm that affect the differentiation of Euglena gracilis. J. Cell Biol. 15, 599.

LinNane, A. W. \& STEWART, P. R. (1967). The inhibition of chlorophyl formation in Euglena by antibiotics which inhibit bacterial and mitochondrial protein synthesis. Biochem. biophys. Res. Commun. 27, $51 \mathrm{I}$.

Lyman, H., Epstein, H. T. \& Schiff, J. A. (196I). Studies of chloroplast development in Euglena. I. Inactivation of green colony formation by u.v. light. Biochim. biophys. Acta 50, 301 .

MCCALlA, D. R. (1967). Isolation and properties of a Euglena mutant resistant to the killing and bleaching effects of N-methyl-N-nitro-N-nitrosoguanidine and some other agents. Biochim. biophys. Acta 142, 2 I9.

MEgo, J. L. (1964). The effect of hadacidin on chloroplast development in non-dividing Euglena cells. Biochim. biophys. Acta 79, $22 \mathrm{I}$.

Mego, J. L. \& Buetow, D. E. (1967). Studies on chloroplast development in heat-bleached Euglena. In: Le Chloroplaste, Croissance et Vieillissement. Ed. by C. Sironval, p. 274. Paris: Masson et Cie.

Pogo, B. G. T. \& Pogo, A. O. (1965). Inhibition by chloramphenicol of chlorophyll and protein synthesis and growth in Euglena gracilis. J. Protozool. 12, 96. 
Robbins, W. J., Hervey, A. \& Stebbins, M. E. (1953). Euglena and vitamin $\mathrm{B}_{12}$. Ann. N.Y. Acad. Sci. 56,818 .

SCHIFF, J. A. \& EPSTEIN, H. T. (1965). The continuity of the chloroplast in Euglena. In: Reproduction: Molecular, Subcellular, and Cellular. Ed. by M. Locke, p. I3I. New York: Academic Press Inc.

Selsky, M. I. (1967). Effects of puromycin aminonucleoside on growth and chloroplast development of Euglena gracilis. Exp. Cell Res. 47, 237.

Stern, J. L., BARner, H. D. \& COHEN, S. S. (I966). The lethality of streptomycin and the stimulation of RNA synthesis in the absence of protein synthesis. J. molec. Biol. $\mathbf{1 7}, \mathbf{1} 88$.

VAZQuEZ, D. \& MonRo, R. E. (1967). Effects of some inhibitors of protein synthesis on the binding of aminoacyl t-RNA to ribosomal subunits. Biochim. biophys. Acta $\mathbf{1 4 2}$, I55.

Zahalsky, A. C., Hutner, S. H., Keane, M. \& Burger, R. M. (I962). Bleaching Euglena gracilis with the anti-histamines and streptomycin-type antibiotics. Arch. Mikrobiol. 42, 46.

Zimmer, C., Triebel, H. \& Thrum, H. (1967). Interaction of streptothricin and related antibiotics with nucleic acids. Biochim. biophys. Acta 145, 742. 